\title{
RESPOSTA À INOCULAÇÃO DE FUNGO SOLUBILIZADOR DE FÓSFORO EM MILHO'
}

\author{
E. NAHAS \\ Departamento de Microbiologia - FACVJ/UNESP, C.P. 245 - CEP: 14870-000 - Jaboticabal,SP \\ D. J. FORNASIERI \\ Departamento de Fütotecnia - FACVJ/UNESP, C.P. 245 - CEP: 14870-000 - Jaboticabal,SP \\ L. C. ASSIS \\ Departamento de Microbiologia - FACVJ/UNESP, C.P. 245 - CEP: 14870-000 - Jaboticabal,SP
}

\begin{abstract}
RESUMO: Este trabalho procurou verificar o efeito da adição de duas fontes de fosfato prontamente disponíveis, superfosfato triplo e fosfato solubilizado obtido por via microbiologica e uma fonte não prontamente disponível, apatita de Araxá, na cultura do millho. Em adição, foi verificado o efeito da inoculação do fungo Aspergillus niger, solubilizador de fosfato de rocha e da adição de matéria orgánica. Nos tratamentos em que se usou matéria orgânica, houve um aumento de população microbiana total do solo, mas nenhum efeito foi observado na produção e absorçăo de fósforo pela cultura do milho. Tanto o superfosfato triplo como a apatita de Araxá permitiram resultados mais favoraveis em termos de produção de massa seca e absorção de fósforo pelo milho em relação ao controle (sem fósforo) e à utilizaçāo de fosfato solubilizado. Tambem nẫo se constatou efeito da inoculação de $A$. niger sobre a solubilização do fosfato de rocha, possivelmente devido à interferência dos microrganismos naturais do solo. $O$ número de microrganismos e a atividade da fosfatase ácida foram menores no solo fertilizado com superfosfato triplo que com apatita de Araxá.
\end{abstract}

Descritores: solubilização de fosfato de rocha, Aspergillus niger, millho

\section{MAIZE RESPONSE TO INOCULATION WITH PSOLUBILIZING FUNGUS}

\begin{abstract}
This paper examined the effect of the addition of two sources of readily available phosphate, triple superphosphate and microbiologically solubilized phosphate, and of a not readily available source, Araxá apatite, on maize crop. In addition, the effects of inoculation of Aspergillus niger, a fungus that solubilizes rock phosphate, and of the addition of organic matter were examined. When organic matter was used, the total microbial population increased, but no effect was observed on phosphorus production or uptake by the maize crop. Both the triple superphosphate and Araxá apatite enhanced the production of dry matter and phosphorus uptake by maize as compared to the control (no phosphorus) and to microbiologically solubilized phosphate. Also, inoculation of $A$. niger had no effect on rock phosphate solubilization, possibly due to the interference of the natural microorganisms of the soil. The number of microorganisms and acid phosphatase activity were lower in the soil fertilized with triple superphosphate than in the soil fertilized with rock phosphate.
\end{abstract}

Key Worls: rock phosphate solubilization, Aspergillus niger, maize

\section{INTRODUÇÃO}

A transformação do fosfato insolúvel, mineral ou orgânico, através dos processos de solubilização ou mineralização, é já conhecida há longo tempo (GERRETSEN, 1948). O processo de solubilização ocorre graças à produção de ácidos orgânicos tanto pelas raízes das plantas
(HOFFLAND et al., 1989), mas, principalmente, por microrganismos do solo que atuam diretamente na dissolução do fósforo ou pela ação quelante sobre os cátions liberando fosfatos solúveis (SPERBER, 1958 e CEREZINE et al. 1988) além de suas necessidades, que podem ser aproveitados pelas plantas. Contudo, os microrganismos heterotróficos solubilizadores

\footnotetext{
1 Trabalho realizado com recursos da FAPESP
}

Sci. agric., Piracicaba, 51(3):463-469, set./dez., 1994 
dependem de uma fonte de carbono e energia para a realização desse processo (NAHAS et al.,1994b).

Dependendo do tipo de solo, o número de solubilizadores varia de 7,1 a $55,6 \%$ do total de bactérias e de 8,1 a $57,9 \%$ do total de fungos (NAHAS et al., 1994a). Da população total de solubilizadores encontrados no solo, algumas espécies tem revelado maior habilidade na dissolução de fosfatos insolúveis (ARORA \& GAUR, 1979). A atividade dos solubilizadores foi comprovada em solo deficiente em fósforo ao qual foi adicionado fosfato de cálcio ou fosfato solúvel, obtendo-se um crescimento igual ou superior com o mineral insolúvel em plantas de Pinus graças à inoculação microbiana (RALSTON \& McBRIDE, 1976). Resultados significativos também foram obtidos pela inoculação de Pseudomonas striata e Aspergillus awamori em culturas de gramíneas adicionadas de fosfato de rocha (GAUR et al. 1980). O efeito da inoculação de Penicillium sp. foi mais efetivo em aumentar a disponibilidade de fósforo que Aspergillus foetidus em solo tratado com fosfato de rocha ou superfosfato triplo, havendo, ainda, melhor resposta à inoculação em termos de matéria seca e captação de fósforo quando foi utilizado o fosfato de rocha (SALIH, 1989).

Objetivou-se nesse trabalho comparar o efeito da inoculação de microrganismo solubilizador de fosfato de rocha com a da aplicação de fosfato solúvel sobre a produção e absorção de fósforo pela cultura de milho. Paralelamente, verificou-se o efeito da adição de matéria orgânica nesses sistemas.

\section{MATERIAL E MÉTODOS}

Solo - foi utilizado um Latossolo Vermelho-Escuro, classe textural franco argilo arenosa, proveniente da Faculdade de Ciências Agrárias e Veterinárias de Jaboticabal - UNESP, com características de baixo conteúdo de fósforo (TABELA 1).

Fosfato de rocha - foi utilizada a apatita de Araxá, que pertence ao grupo das fluorapatitas, apresentando a fórmula $3 \mathrm{Ca}_{3}\left(\mathrm{PO}_{4}\right)_{2} \cdot \mathrm{CaF}_{2}$, baixa solubilidade em água e lenta assimilação.

Inćculo - foi utilizado o fungo Aspergillus niger linhagem $n^{\circ} 26$. A obtenção dos esporos e a sua padronização foi deserita anteriormente (CEREZINE et al. 1988). O fungo foi desenvolvi- do em tubos de ensaio contendo meio de BDA (batata-dextrose-agar), por 7 dias a $30^{\circ} \mathrm{C}$. Após raspagem dos esporos, obteve-se uma suspensão contendo $1,6 \times 10^{8} / \mathrm{ml}$. Foram aplicados $17 \mathrm{ml}$ dessa suspensão por vaso, 14 dias após a semeadura.

TABELA 1 - Características do solo Latossol Vermelho-Escuro".

\begin{tabular}{cl}
\hline Características & Conteúdo \\
\hline Matéria orgânica & $1,9 \%$ \\
$\mathbf{P}$ & $12 \mu \mathrm{g} / \mathrm{ml}$ \\
$\mathrm{K}^{+}$ & $0,08 \mathrm{meq} / 100 \mathrm{~cm}^{3}$ \\
$\mathrm{Ca}^{2+}$ & $1,7 \mathrm{meq} / 100 \mathrm{~cm}^{3}$ \\
$\mathrm{Mg}^{2+}$ & $0,5 \mathrm{meq} / 100 \mathrm{~cm}^{3}$ \\
$\mathrm{H}^{+}+\mathrm{Al}^{3+}$ & $2,5 \mathrm{meq} / 100 \mathrm{~cm}^{3}$ \\
$\mathrm{SB}$ & $2,28 \mathrm{meq} / 100 \mathrm{~cm}^{3}$ \\
$\mathrm{~T}$ & $4,78 \mathrm{meq} / 100 \mathrm{~cm}^{3}$ \\
$\mathrm{~V}$ & $48 \%$ \\
$\mathrm{pH}$ em CaCl & 5,0 \\
\hline
\end{tabular}

- Análise realizada pelo Laboratório de Fertilidade do Solo-FCAVJ/UNESP

Casa de Vegetação - além da adubação com N, K e Zn, foi aplicado fósforo como fosfato solúvel (superfosfato triplo), fósforo como fosfato de rocha (apatita de Araxá) e fósforo solubilizado previamente por A.niger, além do controle (sem fósforo).

As quantidades de nutrientes aplicadas foram as seguintes, por ha: $\mathrm{N}-15 \mathrm{~kg}$ no plantio $e$ $80 \mathrm{~kg} \mathrm{em}$ cobertura, em 2 doses iguais de $40 \mathrm{~kg}$, aos 30 e 50 dias após a emergência das plântulas; $\mathrm{P}_{2} \mathrm{O}_{5}$ - 200kg (superfosfato triplo, apatita de Araxá ou fosfato solubilizado por via microbiológica) ou $100 \mathrm{~kg}$ (superfosfato triplo); $\mathrm{K}_{2} \mathrm{O}-180 \mathrm{~kg} ; \mathrm{Zn}-5 \mathrm{~kg}$; matéria orgânica (palha de milho moída) - 5t e fosfato solubilizado previamente $-180 \mathrm{ml} / 1$ de solo. Para obtenção do fosfato solubilizado, vinhaça não esterilizada foi adicionada na base de $5 \mathrm{~g} / \mathrm{l}$ de fluorapatita e inoculada $\operatorname{com} A$. niger (NAHAS et al. 1990). Após incubação por 9d, o meio de cultura foi filtrado e esterilizado em autoclave. $O$ filtrado apresentou uma concentração de $74,4 \mu \mathrm{g} / \mathrm{ml}$ de fosfato.

Todos os fertilizantes e a palha foram adicionados 1 mês antes da semeadura, exceto o fosfato solubilizado que foi aplicado aos $\mathbf{4 0}$ dias após a semeadura.

A terra foi acondicionada em vasilhames com 6 litros de capacidade e os ensaios conduzidos em casa de vegetação. $O$ teor de umidade foi de 
$50 \%$ da capacidade de campo, favorável para o crescimento dos microrganismos.

Semeadura - após a aplicação dos adubos, o solo foi mantido por 6 dias para alcançar o equilibrio hídrico e a seguir foi feita a semeadura utilizando-se 6 sementes/vaso da variedade IAC Maya de milho (Zea mays $\mathrm{L}$ ), adaptada para solos ácidos. Uma semana após a emergência, foi feito o desbaste, deixando-se 2 plantas/vaso. $O$ cultivo foi feito por 70 dias.

Contagem microbiana - para contagem do número total de bactérias, foi utilizado o meio de BUNT \& ROVIRA (1955) pH 7,4 e para contagem do número total de fungos, o meio de MARTIN (1950), $\mathrm{pH}$ 5,5 , acrescido de $70 \mu \mathrm{g} / \mathrm{ml}$ de rosa de bengala e $0,1 \mathrm{~g} / 1$ de uma mistura das antibióticos penicilina e estreptomicina. A incubação das culturas foi feita a $30^{\circ} \mathrm{C}$ por 2 dias (bactérias) ou 3 dias (fungos).

Atividade das fosfatases ácida e alcalina utilizou-se o procedimento de TABATABAI \& BREMNER (1969), exceto que a concentração do substrato foi $30 \mathrm{mM}$ e os tampões utilizados foram, respectivamente, acetato $0,1 \mathrm{M}$ pH 5,4 e glicina $0,3 \mathrm{M}$ pH 9,0. Uma unidade de atividade enzimática correspondeu à quantidade de enzima que produz $1,0 \mu \mathrm{g}$ de $\mathrm{p}$-nitrofenol $/ \mathrm{min}$. A atividade específica é dada em $\mu \mathrm{g}$ de p-nitrofenol liberado por hora em $1 \mathrm{~g}$ de solo.

Análises químicas do solo - o fósforo total foi determinado pelo método de SOMMERS \& NELSON (1972) e o fósforo orgânico pelo método de ignição (SAUNDERS \& WILLIAMS, 1955). O fósforo disponível, determinado pelo método da resina, e as outras análises basearam-se em RAIJ et al. (1987).

Análises nas plantas - Raízes e parte aérea foram secos em estufa com circulação forçada de ar, a temperatura de $60^{\circ} \mathrm{C}$, até peso constante. As análises de fósforo basearam-se em SARRUGE \& HAAG (1972).

Delineamento experimental e análise estatísticautilizou-se delineamento experimental inteiramente casualizado com 4 repetições e 4 réplicas para as contagens microbianas. A comparação entre médias dos tratamentos foi feita pelo teste de Tukey a $5 \%$. $A$ análise estatística baseou-se em PIMENTEL GOMES (1966).

\section{RESULTADOS E DISCUSSÃO}

Este trabalho demonstrou o efeito da utilização de duas fontes de fosfato prontamente assimiláveis (superfosfato triplo e fosfato solubilizado, obtido previamente pela dissolução da fluorapatita pelo fungo Aspergillus niger) e uma fonte constituída por fosfato de rocha (Apatita de Araxá) na cultura do milho. Além do mais, foi verificado o efeito da inoculação de $A$. niger no solo sobre a solubilização da apatita de Araxá e a adição de matéria orgânica na forma de palha de milho, como fonte de carboris.

Os dados apresentados na TABELA 2 resumem os resultados referentes à contagem microbiana de solo cultivado com milho, fertilizado com diferentes fontes de fósforo, na presença e ausência de matéria orgânica. Tanto bactérias como fungos foram favorecidos pela presença de matéria orgânica, porquanto as maiores contagens de microrganismos referiram-se aos tratamentos em que se adicionou palha de milho no solo. $\mathrm{Na}$ presença de matéria orgânica, maior número de bactérias foi verificado nos solos adicionados de fosfatos prontamente assimiláveis que naqueles adicionados de fosfato de rocha. O maior número de fungos foi verificado no solo adicionado de fosfato de rocha e inoculado $\operatorname{com} A$. niger. Por sinal, este fungo predominou nos tratamentos em que foi inoculado no solo. Na ausência de matéria orgânica, o maior número de microrganismos ocorreu nos solos adicionados de fosfato solubilizado (bactérias) ou na ausência de fósforo (fungos). A adição de superfosfato ao solo desfavoreceu significativamente as contagens de bactérias e fungos, numa proporção menor em que esse fertilizante foi adicionado na metade da dosagem. Os números de microrganismos encontrados se aproximam aos encontrados por NUERNBERG et al. (1984) contudo foram bem inferiores aos obtidos por CATTELAN \& VIDOR (1990) em podzol vermelho-amarelo. A adição de matéria orgânica favoreceu o crescimento microbiano, mostrando maior número de microrganismos que nos solos não adicionados de palha de milho. Confurmando resultados anteriores (NAHAS \& ASSIS, 1991), nos solos adicionados de superfosfato, constatou-se menor número de microrganismos, da mesma forma nos solos inoculados com $A$. niger, houve predominância deste fungo nas contagens dos totais de fungos. A diminuição do número de microrganismos nos solos adubados com superfosfato pode ser uma resposta 
à presença de cádmio nesse adubo (WILLIAMS \& DAVID, 1976).

TABELA 2 - Bactérias e fungos de solo cultivado com milho e submetido a diversas fontes de fósforo.

\begin{tabular}{|c|c|c|}
\hline Fontes de fósforo & $\begin{array}{l}\text { Bactérias } \\
\left(\mathrm{N}^{\circ} \times 10^{5}\right)\end{array}$ & $\begin{array}{r}\text { Fungos } \\
\left(\mathrm{N}^{0} \times 10^{3}\right)\end{array}$ \\
\hline Superfosfato triplo' & 28,25 & 26,71 \\
\hline Superfosfatotriplo-MO ${ }^{b}$ & 45,17 & 133,69 \\
\hline Superfosfatotriplo $1 / 2^{c}$ & 36,50 & 35,92 \\
\hline Superfosfatotriplo $1 / 2-\mathrm{MO}$ & 30,16 & 73,18 \\
\hline Fosfato de rocha & 34,84 & 45,93 \\
\hline Fosfato de rocha-MO & 40,79 & 99,03 \\
\hline Fosfato de rocha-A.niger & 35,04 & 40,44 \\
\hline Fosfato de rocha-A.niger-MO & 42,82 & 217,94 \\
\hline Fosfato solubilizado & 38,95 & 36,78 \\
\hline Fosfato solubilizado-MO & 50,41 & 100,75 \\
\hline Sem fósforo & 37,10 & 82,87 \\
\hline Sem fósforo-MO & 28,65 & 71,57 \\
\hline Teste F & $26,66 * *$ & $30,81^{\infty}$ \\
\hline $\mathrm{CV}(\%)$ & 1,30 & 2,64 \\
\hline DMS Tukey $(P=0,05)$ & 0,49 & 0,72 \\
\hline
\end{tabular}

- - Superfosfato triplo, 200kg $\mathrm{P}_{2} \mathrm{O}_{5} / \mathrm{ha}$

b- MO, matéria orgânica

c- Superfosfato triplo $1 / 2,100 \mathrm{~kg} \mathrm{P}_{2} \mathrm{O}_{5} / \mathrm{ha}$

- Significativo $(P<0,01)$

$O$ efeito de diferentes fontes de fertilizantes fosfatados sobre a absorção de fósforo e produção de massa seca pode ser apreciado na TABELA 3. A maior quantidade de fósforo $(106,2 \mathrm{mg} / \mathrm{vaso})$ foi observada nas plantas cultivadas em solo adicionado de superfosfato triplo. Contudo, essa quantidade não foi diferente da absorvida pelas plantas cultivadas em solo tratado com fosfato de rocha ou superfosfato triplo e matéria orgânica, mas foi significativamente superior aos outros tratamentos. Menor teor de fósforo foi absorvido nas plantas cultivadas na ausência de uma fonte de fósforo ou na presença de fosfato solubilizado. Ainda, menor resposta pode ser constatada nos tratamentos onde foi adicionada palha de milho como fonte de matéria orgânica que aqueles onde não foi adicionada, embora sem diferença estatística. Da mesma forma, não se obteve um efeito diferenciado pela inoculação do fungo $A$. niger no solo adicionado de apatita de Araxá na produção de massa seca e absorção de fósforo, à semelhança dos resultados obtidos por LEE \& BAGYARAJ (1986).

TABELA 3 - Produção de massa seca e absorção de fósforo em milho cultivado em diversas fontes de fósforo.

\begin{tabular}{lcc}
\hline Fontes de fósforo & $\begin{array}{c}\text { Massa seca } \\
\text { (g/vaso) }\end{array}$ & $\begin{array}{l}\text { Fósforo } \\
\text { (mg P/vaso) }\end{array}$ \\
\hline Superfosfato triplo & 98,31 & 106,20 \\
Superfosfato triplo-M & 70,81 & $\mathbf{8 1 , 1 5}$ \\
Superfosfato triplo-1/2 & 72,08 & 74,15 \\
Superfosfato triplo-1/2-MO & $\mathbf{7 1 , 8 1}$ & 71,44 \\
Fosfato de rocha & 89,18 & 99,70 \\
Fosfato de rocha-MO & 84,91 & 64,46 \\
Fosfato de rocha-A.niger & 88,65 & 74,18 \\
Fosfato de rocha-A.niger-MO 83,97 & 77,14 \\
Fosfato solubilizado & 62,91 & 44,52 \\
Fosfato solubilizado-MO & 48,56 & 36,52 \\
Sem fósforo & 62,49 & 45,91 \\
Sem fósforo-MO & 52,86 & 45,40 \\
\hline Teste F & $7,68-$ & $15,16-$ \\
CV (\%) & 15,21 & 15,93 \\
DMS Tukey (P=0,05) & 27,61 & 27,10 \\
\hline
\end{tabular}

${ }^{1}$ ver TABELA 2

- - significativo $(P<0,01)$

Na TABELA 4, foram reunidos os dados referentes ao fósforo disponível (P disponível), fósforo orgânico (P orgânico) e fósforo total (P total) encontrados no solo logo após a colheita das plantas de milho. Com relação ao $P$ disponível, os maiores valores foram encontrados nos tratamentos adicionados de fosfato de rocha e dentre esses quando se adicionou palha de milho ou se inoculou o solo com o fungo Aspergillus niger. Em seguida, vem os resultados da fertilização com superfosfato triplo, que diferiram significativamente do solo adicionado de fosfato de rocha e matéria orgânica e, em último, os tratamentos controle e fosfato solubilizado. Embora não diferindo estatisticamente, pode se constatar que houve influência da adição de matéria orgânica ou de $A$. niger aos solos com fosfato de rocha. Os maiores valores de $P$ orgânico podem ser verificados nos tratamentos com fosfato solubilizado e controle, assim como os menores valores de $P$ total.

A utilização de fosfato solubilizado apresentou, de modo geral, uma resposta 
semelhante ao controle (sem adição de P). Esse tipo de resultado foi inesperado por quanto em trabalho anterior (NAHAS \& ASSIS, 1991) foram obtidos valores de fosfato disponivel semelhantes aos do superfosfato triplo. Da mesma forma, a adição de palha de milho não favoreceu a solubilização e nem o teor de fósforo no solo, provavelmente devido a sua lenta decomposição (MINHONI et al., 1991). Em adição, considerando-se as quantidades absorvidas pelas plantas e a remanescente, aproximadamente $70 \%$ do fósforo aplicado foi fixado.

TABELA 4 - Fósforo residual em solo cultivado com milho e fertilizado com diferentes fontes de fosfato.

\begin{tabular}{lrcc}
\hline Fontes de fósforo $^{1}$ & $\begin{array}{c}\mathbf{P} \\
\text { Disponível } \\
(\mu \mathrm{g} / \mathrm{ml})\end{array}$ & $\begin{array}{c}\mathbf{P} \\
\text { Orgânico } \\
(\mu \mathrm{g} / \mathrm{P} / \mathrm{g})\end{array}$ & $\begin{array}{c}\mathbf{P} \\
\text { Total } \\
(\mu \mathrm{g} \mathrm{P} / \mathrm{g})\end{array}$ \\
\hline Superfosfato triplo & 9,00 & 26,43 & 235,06 \\
Superfosfato triplo-MO & 9,00 & 33,11 & 254,20 \\
Superfosfato triplo-1/2 & 5,00 & 31,49 & 222,79 \\
Superfosfato triplo-1/2-MO & 5,50 & 31,27 & 220,34 \\
Fosfato de rocha & 10,50 & 23,07 & 227,21 \\
Fosfato de rocha-MO & 12,50 & 23,81 & 240,46 \\
Fosfato de rocha-A.niger & 11,00 & 24,97 & 239,97 \\
Fosf. de rocha-A.niger-MO11,50 & 19,59 & 243,90 \\
Fosfato solubilizado & 3,22 & 31,48 & 213,65 \\
Fosfato solubilizado-MO & 3,50 & 38,41 & 196,30 \\
Sem fósforo & 2,00 & 35,01 & 198,74 \\
Sem fósforo-MO & 4,25 & 34,47 & 198,26 \\
\hline Teste F & $32,25 *$ & $26,74 * *$ & 91,43 \\
CV (\%) & 17,09 & 11,11 & 4,60 \\
DMS Tukey (P=0,05) & 3,13 & 7,71 & 24,39 \\
\hline
\end{tabular}

' ver TABELA 2

- significativo $(P<0,01)$

A TABELA 5 mostra que os resultados da atividade da fosfatase ácida foram bem superiores aos da fosfatase alcalina. A maior atividade foi constatada nos solos adicionados de fosfato de rocha e em seguida nos tratamentos adicionados de matéria orgânica. Confirmando ROJO et al. (1990), constatou-se predominância da atividade da fosfatase ácida sobre a fosfatase alcalina, possivelmente devido ao índice de $\mathrm{pH}$ ácido do solo utilizado neste trabalho. A maior atividade das fosfatases nos solos adicionados de fosfato de rocha e matéria orgânica pode ser decorrente, respectivamente, $\mathrm{da}$ inibição $\mathrm{da}$ atividade enzimática em presença de fosfato solúvel (NAHAS
\& ASSIS, 1992,) ou do efeito da adição de uma fonte de fosfato orgânico não disponível (NAHAS et al. 1982) ou, ainda, do efeito do cádmio proveniente do superfosfato (JUMA \& TABATABAI, 1977).

TABELA 5 - Atividade das fosfatases ácida e alcalina em solo cultivado com milho e adubado com diferentes fontes de fósforo.

\begin{tabular}{lcr}
\hline Fontes de fosforo & $\begin{array}{c}\text { Fosfatase } \\
\text { ácida } \\
\left(\mu \mathrm{g} \mathrm{PNF}^{+} / \mathrm{h} . \mathrm{g} \text { solo) }\right.\end{array}$ \\
\hline Superfosfato triplo & $\begin{array}{r}\text { Fosfatase } \\
\text { alcalina }\end{array}$ \\
Superfosfato triplo-MO & 231,18 & 105,41 \\
Superfosfato triplo-1/2 & 274,02 & 99,74 \\
Superfosfato triplo-1/2-MO & 235,82 & 62,89 \\
Fosfato de rocha & 324,74 & 93,30 \\
Fosfato de rocha-MO & 306,18 & 36,45 \\
Fosfato de rocha-A.niger & 462,11 & 128,87 \\
Fosf. de rocha-A.niger-MO & 291,49 & 45,62 \\
Fosfato solubilizado & 318,81 & 109,54 \\
Fosfato solubilizado-MO & 213,40 & 97,43 \\
Sem fósforo & 320,10 & 37,11 \\
Sem fósforo-MO & 259,79 & 77,06 \\
\hline Teste F & $29,27^{-}$ & $17,31^{-}$ \\
CV (\%) & 11,06 & 19,55 \\
DMS Tukey (P=0,05) & 76,82 & 41,65 \\
\hline
\end{tabular}

1 ver TABELA 2

+ - p-nitrofenol

- significativo $(P<0,01)$

Os dados da TABELA 6 mostram que as bactérias sofreram a influência de todos os parâmetros do solo, exceto $P$ disponível enquanto que os fungos foram dependentes dos teores de $P$ orgânico e P total. A atividade da fosfatase ácida foi dependente da população microbiana mas não a fosfatase alcalina. $O P$ disponível não se correlacionou com nenhuma das variáveis analisadas. A atividade da fosfatase ácida foi dependente dos teores de $\mathrm{P}$ orgânico e P total. A inclusão de fosfato de rocha em solo cultivado com tomateiro aumentou a população bacteriana solubilizadora de fosfato bicálcico (MACHADO et al. 1983). Esse tipo de efeito pode ter ocorrido nos solos fertilizados com apatita de Araxá, não se constatando, portanto, diferença com os solos inoculados com $A$. niger. 
TABELA 6 - Correlação entre os parâmetros químicos e biológicos de solo cultivado com milho.

\begin{tabular}{|c|c|c|c|c|}
\hline $\begin{array}{l}\text { Parâmetros } \\
\text { do solo }\end{array}$ & Bactérias & Fungos & $\begin{array}{c}\text { Fosfatase } \\
\text { acida }\end{array}$ & $\begin{array}{r}\text { Fosfatase } \\
\text { alcalina }\end{array}$ \\
\hline P disponivel & $-0,0$ ons $^{2}$ & $0,04^{\mathrm{NS}}$ & $0,19 \mathrm{Ns}$ & $0,08^{\mathrm{Ns}}$ \\
\hline P orgênico & 0,65 & $0,46^{* *}$ & $0,28^{*}$ & $0,08^{\text {NS }}$ \\
\hline P total & $0,81^{* *}$ & $0,62^{*}$ & 0,65 & $0,14^{\mathrm{NS}}$ \\
\hline $\begin{array}{l}\text { Fosfatase } \\
\text { alcalina }\end{array}$ & $0,08^{\mathrm{NS}}$ & $-0,25^{\mathrm{Ns}}$ & $0,24^{\mathrm{NS}}$ & - \\
\hline $\begin{array}{l}\text { Fosfatase } \\
\text { acida }\end{array}$ & $0,5 T^{\circ}$ & $0,33^{*}$ & - & - \\
\hline
\end{tabular}

Ns - Nāo significativo

- Significativo $(P<0,05)$

* - Significativo $(P<0,01)$

\section{CONCLUSÕES}

Não foi constatado efeito da inoculação de A. niger ou da adubação com matéria orgânica na dissolução de fluorapatita. Tanto superfosfato triplo como fosfato de rocha proporcionaram a mesma produção de massa seca e absorção de fósforo pela cultura de milho, porém, em níveis superiores ao controle. Nos tratamentos em que foi adicionada matéria orgânica houve um aumento do número de bactérias e fungos.

\section{REFERÊNCIAS BIBLIOGRÁFICAS}

ARORA, D.; GAUR, A. C. Microbial solubilization of different inorganic phosphates. Indian Joumal Experimental Biology, New Delhi, v.17, p.1258-1261. 1979.

BUNT, J.S.; ROVIRA, A.D. Microbiological studies of some subantartic soils. Joumal of Soll Science, Oxford, v.6, p.119-128, 1955.

CATTELAN, A.J.; VIDOR, C. Flutuaçóes na biomassa, atividade e população microbiana do solo, em função de variaçōes ambientais. Revista Brasileira de Ciência do Solo, Campinas, v.14, p.133-141, 1990.

CEREZINE, P.C.; NAHAS, E.; BANZATTO, D.A. Soluble phosphate accumulation by Aspergillus niger from fluorapatite. Applied Microbiology and Biotechnology, Berlin, v.29, p.501-505. 1988.

GAUR, A.C.; MATHUR, R.S.; SADASIVAM, K.V. Effect of organic materials and phosphate-dissolving culture on the yield of wheat and greengram. Indian Journal Agronomy, New Delhi, v.5, p.501-503, 1980.
GERRETSEN, F.C. The influence of microorganisms on the phosphate uptake by the plant. Plant and Soil, The Hague, v.1, p.51-81, 1948.

HOFFLAND, E.; FINDENEGG, G.R.; NELEMANS, J. A. Solubilization of rock phosphate by rape. I. Evaluation of the role of the nutrient uptake pattern. Plant and Soll, The Hague, v.113, p.155-160, 1989.

JUMA, N. G.; TABATABAI, M.A. Effects of trace elements on phosphatase activity in soils. Soll Science Society America Journal, Madison, v.41, p.343-346, 1977.

LEE, A.; BAGYARA, D.J. Effect of soil inoculation with vesicular-arbuscular mycorrhizal fungi and either phosphate rock dissolving bacteria or thiobacilli on dry matter production and uptake of phosphorus by tomato plants. New Zealand Journal Agricultural Research, Wellington, v.29, p.525-531. 1986.

MACHADO, J.O.; PICCIN,C.R.; BARBOSA,J.C.; NAHAS, E. Ação da vinhaça e fosfato natural sobre a população de bactérias solubilizadoras de fosfato bicálcico, habitantes' da rizosfera de Lycopersicon esculentum (Mill.) cv "Petomech". Cientifica, Jaboticabal, v.11, p.63-69, 1983.

MARTIN, J.P. Use of acid, rose bengal, and streptomycin in the plate method for estimating soil fungi. Soil Science, Baltimore, v.69, p.215-232, 1950.

MINHONI, M.T.A.; CARDOSO, E.J.B.N.; EIRA, A.F. Efeito de cinco tipos de matéria orgânica na solubilização microbiana de fosfato de rocha. Revista Brasileira Citencia do Solo, Campinas, v.15, p.29-35, 1991.

NAHAS,E.; TERENZI, H.F.; ROSSI, A. Effect of carbon source and $\mathrm{pH}$ on the production and secretion of acid phosphatase (EC 3.1.3.2) and alkaline phosphatase (EC 3.1.3.1.) in Neurospora crassa. Jourmal of General Microbiology, Reading, v.128, p.2017-2021, 1982.

NAHAS, E.; ASSIS, L.C. Efeito da adição ao solo de fosfato solúvel obtido por via microbiológica a partir de fluorapatita. Revista Latino-americana de Microbiologia, México, v.33, p.225-229, 1991.

NAHAS, E.; ASSIS, L.C. Efeito da concentraçåo de fosfato na solubilizaçăo de fluorapatita por Aspergillus niger. Revista de Microbiologia, São Paulo, v.23, p.37-42, 1992.

NAHAS, E.; BANZATTO, D.A.; ASSIS, L.C. Fluorapatite solubilization by Aspergillus niger in vinasse medium. Soil Biology and Biochemistry, Oxford, v.22, n.8, p.1097-1101, 1990. 
NAHAS, E.; CENTURION, J.F.; ASSIS, L. C. Efeito das características fisicas e químicas dos solos sobre a população microbiana. Revista Brasileira de Ciencia do Solo, Campinas, v.8, n.1, 1994a (no prelo).

NAHAS, E.; CENTURION, J.F.; ASSIS, L.C. Microrganismos solubilizadores de fosfato e produtores de fosfatases de vários solos. Revista Brasileira de Ciencia do Solo, Campinas, v.18, n.1, $1994 b$ (no prelo).

NUERNBERG, N.J.; VIDOR, C.; STAMMEL, J.G. Efeito de sucessōes e tipos de adubação na densidade populacional e atividade microbiana do solo. Revista Brasileira de Ciência do Solo, Campinas, v.8, p.197-203, 1984.

PIMENTEL GOMES, F. Curso de estatística experimental. Piracicaba: ESALQ, 1966. 404p.

RAIJ, B. van et al. Anślise química do solo para fins de fertilidade. Campinas: Fundação Cargill, 1987.170p.

RALSTON, D.B.; Mc BRIDE, R.P. Interaction of mineral phosphate-dissolving microbes with red pine seedlings. Plant and Soil, The Hague, v.45, p.493-507, 1976.

ROJO, M.J.; CARCEDO, S.G.; MATEOS, M.P. Distribution and characterization of phosphatase and organic phosphorus in soil fractions. Soil Biology an Biochemistry, Oxford, v.22, p.169-174, 1990.

SALIH, H. M. Availability of phosphorus in a calcareous soil treated with rock phosphate or superphosphate as affected by phosphate-dissolving fungi. Plant and Soil, The Hague, v.120, p.181-185, 1989.
SARRUGE, J.R.; HAAG, H.P. Andlíses quimicas em plantas. Piracicaba: ESALQ, 1972. 56p.

SAUNDERS, W.M.H.; WILLIAMS, E.G. Observations on the determination of total organic phosphorus in soil. Journal of the Soil Science, Oxford, v. 6, p.254-267, 1955.

SOMMERS, L.E.; NELSON, D.M. Determination of total phosphorus in soils: a rapid perchloric acid digestion procedure. Soil Science of America Proceedings, Madison, v.36, p.902-904, 1972.

SPERBER,J.I. Solution of apatite by soil microorganisms producing organic acids. Australian Journal of Agricultural Research, Melbourne, v.9, p.782-787, 1958.

TABATABAI, M.A.; BREMNER, J.M. Use of p-nitrophenylphosphate for assay of soil phosphatase activity. Soil Biology and Biochemistry, Oxford, v.1, p.301-307, 1969.

WILLIAMS, C.H.; DAVID, D.J. The accumulation in soil of cadmium residues from phosphate fertilizers and their effect on the cadmium content of plants. Soil Science, Baltimore, v.121, p.86-93, 1976.

Recebido para publicação em 20.01.94

Aceito para publicação de 10.03 .94 